\title{
Self-Employed Graduate Entrepreneurs And Management Of Small And Medium Enterprises (SMEs) In Lagos State, Nigeria
}

Ololade Kazeem Shonubi, University of Johannesburg, South Africa Saheeb Oluwafemi Taiwo, Lagos State University, Nigeria

\begin{abstract}
This paper examines what enables self-employed entrepreneurial graduates to successfully manage their businesses despite that they never had formal education in any management course(s) but thrive within an environment full of unforeseen uncertainties, such as lack of business incentives, unfavorable government policies, inadequate infrastructures in Nigeria, to mention but a few. In adopting Okala's in-built myths of entrepreneurs, the quantitative approach of research was utilized with a cluster sampling technique to select 427 small and medium scale entrepreneurs in Lagos State, Nigeria. The chi-square method of data analysis used as a method of data analysis indicates that in-born traits, risk-taking and entrepreneurial learning contribute to SME success. Herron and Robinson's (1993) theory was adapted to explain what makes entrepreneurs succeed. It was recommended that to be successful as managers, every unsuccessful SME manager should look inward and attempt to discover some in-born management characteristics that lie within them to be a successful manager.
\end{abstract}

Keywords: Entrepreneur; Self-Employed; Small-Medium Scale Enterprise; Management Functions; Informal Management Skills, Self-Motivation; Leadership and Personality Traits

\section{INTRODUCTION}

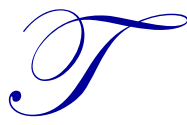

he objective of this study was to investigate the relationship between non-acquisitions of formal management experience by university self-employed graduate entrepreneurs and therefore describe reasons for their successful management of Small and Medium Enterprises (SMEs) in Lagos stateNigeria, despite that there including poor knowledge-based economy, lack of entrepreneurship teachers, materials and equipment, unavailability of funds, and non-inclusion of entrepreneurship programs in the school curricula (Oviawe, 2010). In this study, the context of entrepreneurship is considered within the SME limit. The roles of entrepreneurships in economic development and poverty reduction, particularly in developing countries, have been affirmed through avalanche of literature. In many countries worldwide, SMEs contribute significantly to growth and development, as manifested by their Gross National Products (GDP) base and they also account for $70 \%$ of national employment, job creation and economic growth (Organization of Economic Cooperation and Development OECD, 2004). Further, Nigeria SMEs are assumed to constitute $99 \%$ of existing enterprises, just as the economy of many countries worldover are usually sustained through entrepreneurship development (Ogunsiji and Ladanu, 2010).

According to Hamerlinck and Emery (2006), an international study indicates that the direct correlation between the level of entrepreneurial activity and economic growth is greater than $70 \%$ in the United States of America. More so, entrepreneurial development is multi-dimensional; that is, it does not only depend on the traditional economic model of factor inputs, but issues such as culture, gender, type of enterprises, etc. need be considered (Galbraith, 2008). Entrepreneurial experts agree that philosophical thoughts and values are preserved and transmitted during pre-colonial, colonial, and post-colonial Nigeria and that they encourage the uprightness of their citizens as they grow to be entrepreneurial managers. These values are transmitted through wise sayings, proverbs, 
aphorisms, coded clauses and experiential narrations; religious beliefs, principles, doctrines and practices, ancient fables, stories and folklores, poems, etc.; reflective songs, powerful orations, incantations, etc.; mythology and memories of elderly people and shared-cultural values, e.g. shared customs, sayings, taboos, and superstitious (Ayozie and Latinwo, 2010).

It is a common experience that about $80 \%$ of the graduates from Nigerian universities find it very difficult to seek employment every year, partly due to the curricula of the universities and other tertiary institutions, which lay emphasis on training for white collar jobs rather than teaching and conducting research on entrepreneurship and innovation centers and developing the capacity of staff and students in entrepreneurship and innovation in tertiary institutions. These inadequacies have led to Nigerian tertiary institution graduates' decisions for self-employment (Ameseghan and Tayo-olajubutu, 2009). Makhbul and Hasun (2011) and Ekpe (2011) stress that an important factor contributing to a successful entrepreneur is knowledge that is gained from various sources, such as training or personal experience through formal or informal education. As such, classroom theoretical knowledge should be supported with practical business education/training through internships in small businesses, which enables necessary theoretical background to combine with practical skills.

However, entrepreneurial competence does not only depend on skills of writing a business plan, but also recognizing and acting on new opportunities. That competence is also acquired at birth; that is, performance of an entrepreneur may also be influenced by in-born personality and abilities (Ekpe, 2011). Arogundade (2009) points out that capital is one of the principal factors hindering entrepreneurship practices. Others are unhealthy macroeconomic environment, which is detrimental to unstable and virile entrepreneurship development; the fear of failure to take risks, and 3) the poor state of infrastructural development provided by the government, which affects the level of productivity and entrepreneurial activities in the country.

To find answers to the puzzle of this paper, the following hypotheses were tested:

Research Question 1: What is the relationship between in-born psychological traits and the success of SME managers?

Hypothesis 1: There is no significant relationship between in-born psychological traits and the success of SME managers.

Research Question 2: What is the relationship between the ability to take risks and the success of SME managers?

Hypothesis 2: There is no significant relationship between the ability to take risks and the success of SME managers.

Research question 3: What is the relationship between informal entrepreneurial management learning and the success of SME managers?

Hypothesis 3: There is no significant relationship between informal entrepreneurial management learning and the success of SME managers.

\section{Who is an Entrepreneur?}

Indeed, within the field of entrepreneurship research, more empirical studies involving characteristics of entrepreneurs have been conducted than almost any other kind; but in practice, there are many possible and equally plausible definitions of what/who an entrepreneur is. Often the term entrepreneurship is equated to new venture creation and small business management. Most neo-classical economists recognize that there are three primary economic factors of production - raw materials, labor, and capital. These components have to be brought together by individuals. Some economists regard entrepreneurship as a kind of fourth factor which acts on the other three to combine them in productive ways (Ngunjiri, 2010). Going by Lewis (2006), Oviawe (2010), and Mordi, Simpson, Singh \& Okafor's (2010) definition, among others, entrepreneurs tend to have a number of common traits, which include characteristics concerning creativity and innovation, foresight, imagination, and risk-taking. Hence, the 
concept of an "entrepreneur" is derived from the French word 'entreprendre', which has its root as a concept of 'between-taker or go-between'.

Kuratko and Hodgetts (2004) describe an entrepreneur as a creator of new venture and one who faces uncertainty in many ways. Entrepreneurs are individuals who engage in activities related to a firm's ownership and management and have the capability to foresee opportunities, gather the needed resources - time, energy and money - and take actions necessary to ensure success (Makhbul and Hasun, 2011). Studies have shown that an entrepreneur must have natural drive for achievement, possess internal locus of control, self-confidence, independence, innovativeness, good communication and decision-making skills, must be willing to take risks, possesses high selfefficacy, opportunity recognition, perseverance and social skills, honesty, trust, accountability, spirituality, good ethics, determination, flexibility, and knowledge ability (Makhbul and Hasun, 2011). Leadership, as a sub-set of management's functions, is also one of the pertinent factors that contribute extensively to the success of entrepreneurs. Good managers need to exhibit functional leadership competencies in operations, finance, marketing, and human resources, as well as self competencies, such as intellectual integrity and promotion of their business domain, rather than themselves.

\section{Management and Entrepreneurship}

SME managers often possess a high propensity to over-estimate their intuition. The development of special management tools is, however, necessary - not for substituting the existing management styles, but rather for supporting the intuitive management of entrepreneurs (Fink and Hatak, 2010). In established businesses, management practices would have been intuitively developed over a number of years, but because different people have different conceptions of what management is all about, that inevitably shapes their views about the way in which managers ought to learn and be developed. This often gives rise to a number of contradictions and tensions. There is a fundamental distinction to make between, on the one hand, the models, theories, techniques, and tools that underpin management in one context and, on the other hand, the day-to-day lived experiences of those performing management functions in organizations. The former view of management may focus on subjects such as accounting, finance, marketing, or human resource management, supplemented by skills or competencies, such as time management, planning, or problem-solving. The latter view of management is far less-structured and refers to what managers have to do in a particular place and at one point in time. Factors such as the organization, environment, manager's personality and style, affect what the manager does and how they learn to do it (Devins, Gold, Johnson and Holden, 2005).

McNamara (2008) states four common processes that managers must follow: 1) Planning - identifying the needs of an organization and determining the goals, objectives, and resources needed to carry out the planned tasks, responsibilities, and dates for completion of tasks; 2) Organizing Resources - allocation of resources and assignment of tasks in accomplishing organizational goals. In the process of organizing, managers arrange a framework that links all workers, tasks, and resources together so that the organizational goals can be achieved; 3 ) Leading - setting direction for the organization, groups, and individuals as well as influencing organizational staff to follow that direction, e.g. establishing strategic direction (vision, values, mission, and/or goals) and championing methods of organizational performance management to pursue that direction and; Controlling or Coordinating self-structuring of the organizational system to effectively and efficiently reach goals and objectives in the form of feedback, monitoring, and adjustment of systems accordingly. Examples include the use of financial controls, policies and procedures, and performance management processes (McNamara, 2008).

Generally, management of an SME is usually learned; that is, inextricably linked to the performance of work activities in business, solving problems, and grasping new opportunities as they arise. Research reflects the nature of learning in an on-going SME business context and learning is largely informal or incidental, driven by the desires of those involved and seldom reliant upon formal or structured training. Sometimes SME business managers create deliberate attempts to experiment and acquire new knowledge, but more often than not, learning is the byproduct of a business process rather than the focus of the process itself. As work proceeds and learning accumulates, the meanings derived are shared among those who participate, thus forming the distinct culture of a business that develops over time (Devins, Gold, Johnson and Holden, 2005). 
Some people, other than the manager and employees, provide a context for learning to take place. For instance, a small business has been conceptualized as a learning organization operating within a network interdependent of others, including family members, friends, professional bodies, and other stakeholders. These "close others" have a significant interest in the workings of the business but are not involved in its day-to-day operations, except perhaps on special occasions or in times of difficulty. "Close others" may include family, friends, or other stakeholders, such as particularly valued suppliers or customers. This group forms the outer context of the business learning environment. In addition to specific help and assistance, "close others" can provide informal learning opportunities through a sounding board or mentoring either at work or in a "safe environment. Also, networks and networking are increasingly viewed as major learning opportunities for smaller enterprises and they are seen as a crucial element of successful small business development.

The emphasis of the relevance of acquiring formal management knowledge and experience is also highlighted in Okala's (2004) definition of entrepreneurship. Okala (2004) defines entrepreneurial management as the process of planning and organizing a small business venture through the control of resources to create, develop, and implement solutions to problems of the society. Moreover, the myth that managers are born and not made is usually faced by an entrepreneur who does not receive corporate support or have formal management experience. That, in reality, is what makes entrepreneurs accumulate relevant skills, know-how, experience, and contact through intuitive abilities over a period of time, which results in self-development in management procedures and skills. Okala (2004) adds that successful entrepreneurs take careful and calculated risks, but they do not deliberately take unnecessary risks, nor do they shy away from unavoidable risk. Moreover, highly successful entrepreneurs build a team, an organization, or a company by learning through partners, suppliers, creditors, and families.

The above myths of an entrepreneur are borne out of the traits or characteristics required to be exhibited by an entrepreneur in the achievement of success in business. The requirements of these myths, as enumerated by Okala (2004), are that entrepreneurs must be decisive, disciplined, and tenacious; have the will to sacrifice; be able to immerse him or herself totally into his/her enterprise; be self-starters, team builders, superior learners, and teachers; have intimate knowledge of customers' needs, be market-driven, and must be obsessed with value creation and enrichment; must be calculated risk-takers and be able to solve problems; must be open-minded, restless with their status-quo; able to learn quickly; highly adaptable, creative, skilled at conceptualizing, attentive to details and must have a clear result orientation; set high, but realistic goals; have a strong drive to achieve, know his or her personal weaknesses and strengths and; focus on what can be done rather than the reason(s) things cannot be done.

Research findings have suggested that SME businesses do not generally have a management structure that requires a management development policy or system, but only a policy of self-development for the owner manager (Devins, Gold, Johnson and Holden, 2005). Some economists, sociologists, psychologist, management scientists, etc. assume that there exists a set of personalities required of SMEs to take care of their shortcomings in order to succeed in their business. Thus, it is necessary to understand the theoretical framework which is featured and explained below.

\section{Theoretical Insights of the Study}

A consistent universal theory does not exist in entrepreneurship (Grant and Perren, 2002), but rather, it consists of several different approaches, including psychology, management, sociology, anthropology, regional science, and economics. No common theoretical framework exists, even if demanded rigorously to synthesize the different points of view toward theorizing entrepreneurship. Some trials to develop a multi-dimensional approach to entrepreneurship mainly studied the problems from the perspective of the above-mentioned and well-established disciplines (Johnson, 1990). Therefore, this study will be framed by adopting the theoretical model of Herron and Robinson (1993) in understanding the combinations of variables that could engender entrepreneurial success within the context of Lagos State, Nigeria.

In Figure 1, personality traits do not only engender motivation and entrepreneurial processes of management, but their causal link to performance is further modified by context. Context is the environment within which the behaviors take place and which sets the requirements that link behaviors with performance. 


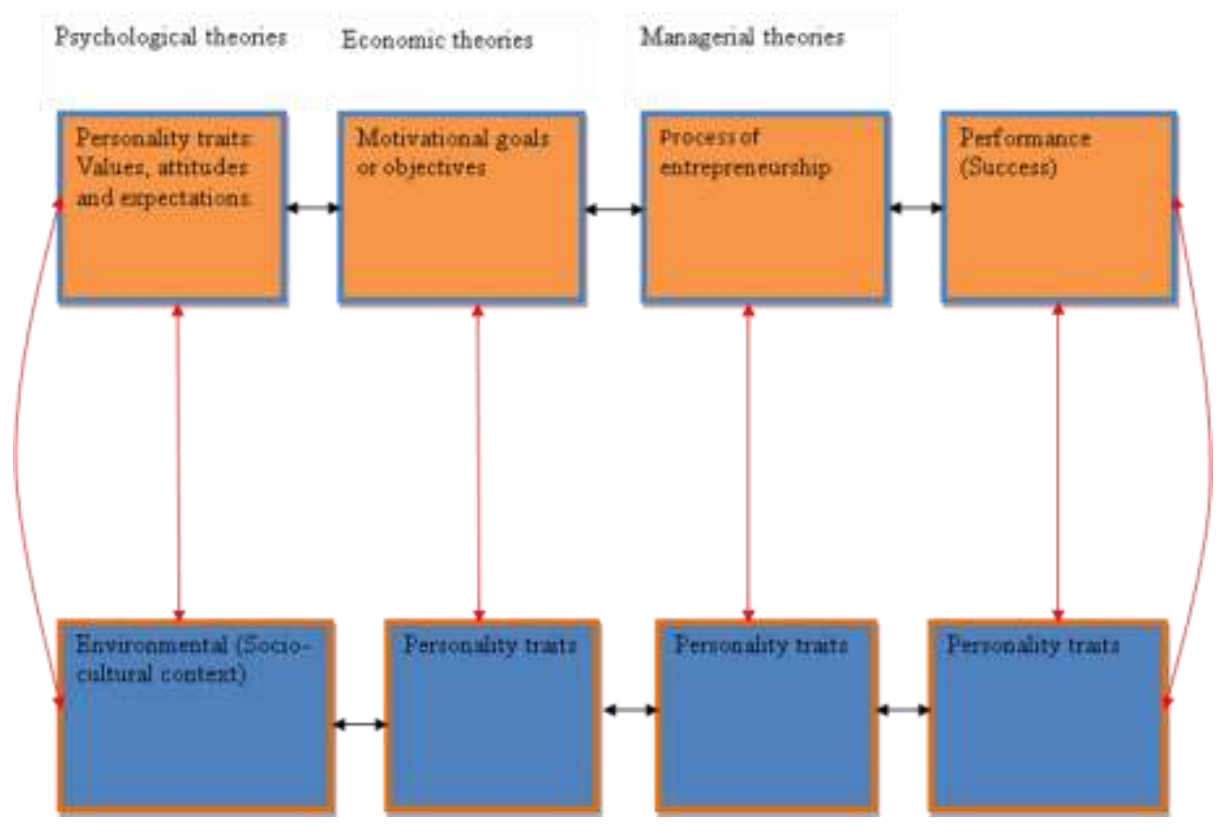

Figure 1: Theoretical Model of Entrepreneur Success (Adapted from Herron and Robinson, 1993)

Personality traits can be used to modify the environmental business variables by the entrepreneur, but sometimes with difficulty. For instance, the entrepreneur may determine his/her external environmental structure at the onset of a venture and then find it more difficult to modify this environment once the venture begins to develop. By implication, the modification strategies are subsequent to venture creation through the determined efforts of the entrepreneur via personal traits - intuitive abilities (Herron and Robinson, 1993).

Unlike personality traits, motivation is not a direct observable construct. Motivation combines with abilities in order to determine behavior to achieve behavioral quality. More so, motivation will also be heavily influenced by social learning through observation of others. For instance, if one's father had been an entrepreneur, social learning might create expectations of a certain level of success, thus effecting motivation either directly - as a mediator or moderator - or, more likely, the combination of two or all three (Devins, Gold, Johnson and Holden, 2005). Nevertheless, natural ability resulting from an entrepreneur's behavior results in managerial theories, giving rise to the exhibition of managerial elements of planning, organizing, coordination, recruitment, budgeting, control, etc. This ultimately results in causal link between managerial behavior and performance (which is contingent upon situational context) which, in turn, determines the behavior of the entrepreneur (Herron and Robinson, 1993).

The authors of this paper argue that the conscious process of interaction and combination of the variables in the adapted theoretical model of Herron and Robinson (1993) may contribute to entrepreneurial success in as much as the personality traits could instinctively give rise to the following models: psychological, sociological, economic, and managerial theories/models formulated by scholars in the area of entrepreneurship research.

\section{RESEARCH DESIGN AND METHODS}

According to Maree and Pieterson (2007) and Cohen, Manion, and Morrrison (2007), survey design of research is used to learn peoples' attitudes, beliefs, values, demographics, behavior opinions, habits, desires, ideas, and any other types of information in the field of research. Hence, the survey design was utilized for the purpose of understanding and describing how SME managers succeed in Lagos State, Nigeria. The target population of this study comprised of Artisan, Arts, Science, Social Sciences, Engineering, Law, Education, and Agricultural Science graduates who did not receive or experience any formal management teaching in their undergraduate university days and thereafter. 
The respondents were carefully sampled from a cluster of two international markets - the Auto Spare Parts and Machinery Dealers Association Market (ASPAMDA) and Alaba International Market (both of which are located along Lagos-Badagry Expressway and in Ojo LGA). These markets comprise of electronics, automobile spare parts, textiles and clothing, electrical appliances, cosmetics, machinery, furniture sections, etc. The sampling of the respondents was based on a purposive snowball technique.

The approached respondents requested to participate in the study were purposively sampled because they identified themselves as SME managers who have never received any formal management lessons or classes during or after their university education days. Successive respondents sampled were also instrumental to the identification of other respondents who are of their similar status through snowball sampling. This is to ensure that the 427 respondents sampled from the different sections of the market are identified as those not formally trained management graduates. Among the sample, 300 were male while 127 were female SME managers with at least five years of business experience.

To secure the needed information, a two-section questionnaire tagged "Informally Trained SME Graduates Manager Questionnaire" (ITSMEGMQ) was constructed and utilized for the collection of data, in analyzing the relationship between non-formally trained SME graduate managers in order to adduce reasons for their success as entrepreneurs. Section A dealt with personal data of the respondents, such as age, sex, years of experience as a SME manager, and product specialization. Section B was based on a four-point Likert Scale of Strongly Agree, Agree, Disagree, and Strongly Disagree and contained items seeking answers to what prompts informally trained managers to succeed in their businesses. More so, items in the instrument revolve around in-born personality traits, the ability to take risks, and informal learning; and the questionnaire was validated through the input of colleagues and professors in the field of Economics and Management Science at the University of Pretoria.

The reliability of the instrument was established using a test-retest method and Pearson Product Moment Correlation (PPMC) statistical analysis which produced a reliability coefficient $r$ of .72. A Chi-square statistical technique was also used to test the null hypotheses, and in all the tests of the hypotheses, the 0.05 confidence level was used to determine statistical significance.

\section{ANALYSIS OF RESULTS}

Hypothesis 1: There is no significant relationship between in-born psychological traits and the success of SME managers.

Interpretation of Results

At 0.5 level of significance and 3-degree of freedom, the chi-square analysis shows that the calculated value of 19.23 is greater than the chi-square critical value of 7.82 (see Table 1); hence, the hypothesis is rejected. As a result, there is a significant relationship between in-born psychological traits and the success of SME. Hence, the result indicates that in-born traits of graduates enhance their management ability and business success of entrepreneurs who have never received formal training in management during and after their university years as undergraduates.

Table 1: Relationship Between In-Born Characteristics And Entrepreneurial Success

\begin{tabular}{|l|c|c|c|c|c|c|c|}
\hline Variable & SA & A & D & SD & DF & $\mathbf{X}^{2} \mathbf{C a l}$ & $\mathbf{X}^{\mathbf{2}} \mathbf{C r i t}$ \\
\hline In-born psychological traits & 123.7 & 131.4 & 81.6 & 86.7 & 3 & 19.23 & 7.82 \\
\hline
\end{tabular}

Hypothesis 2: There is no significant relationship between the ability to take risks and the success of SME managers.

Interpretation of Results

Since the chi-square calculated value of 52.67 is greater than the critical value of 7.82 at 0.05 level of significance and 3-degree of freedom (see Table 2), the hypothesis is rejected. Hence, there is a significant 
relationship between the ability to take risks and the success of SME managers. By implication, non-formally trained graduate entrepreneurs who possess the ability to take risks necessarily succeed as SME managers.

Table 2: Relationship Between The Ability To Take Risks And Success

\begin{tabular}{|l|c|c|c|c|c|c|c|}
\hline Variable & SA & A & D & SD & DF & $\mathbf{X}^{2} \mathbf{C a l}$ & $\mathbf{X}^{\mathbf{2}} \mathbf{C r i t}$. \\
\hline Ability to take risks & 138.6 & 149.1 & 75.2 & 64.1 & 3 & 52.67 & 7.82 \\
\hline
\end{tabular}

Hypothesis 3: There is no significant relationship between informal entrepreneurial management learning and the success of SME managers.

Interpretation of Results

At 0.05 level of significance and 3-degree of freedom, the results in Table 3 show that chi-square calculated value of 8.83 is higher than the critical value of 7.82 ; hence, the hypothesis is rejected. As a result, there is a significant relationship between informal entrepreneurial management learning and the success of SME managers.

Table 3: Relationship Between Informal Entrepreneurial Management Learning And Success

\begin{tabular}{|l|c|c|c|c|c|c|c|}
\hline Variable & SA & A & D & SD & DF & $\mathbf{X}^{2}$ Cal. & $\mathbf{X}^{2}$ Crit. \\
\hline Informal entrepreneurial management learning & 121.9 & 119.8 & 85.7 & 99.6 & 3 & 8.38 & 7.82 \\
\hline
\end{tabular}

\section{DISCUSSION OF RESULTS}

The findings in Table 1 indicate that the relationship between in-born characteristics and entrepreneurial success was statistically significant. This finding is consistent with the natural factors used to describe an entrepreneur, as stressed by Makhbul and Hasun (2011) when they summarized the findings of a study that an entrepreneur must have a drive for achievement and must possess internal locus of control, self-confidence, independence, innovativeness, good communication and decision-making skills, high self-efficacy, opportunity recognition, perseverance, social skills, honesty, trust, accountability, spirituality, good ethics, determination, and flexibility. The natural possession of these in-born characteristics, in turn, metamorphosis into instinctive key managerial functions, such as planning, organizing, directing, and controlling, so that the SME achieves the desired goals of his/her business organization (http://www.answers.com/topic/management).

In addition, the findings also agree with Okala's (2004) consequence of traits/characteristics which inadvertently produce commitment and determination, leadership, opportunity obsession, tolerance of risk, ambiguity and uncertainty, creativity self-reliance and ability to adapt, and motivation required to be exhibited by SME managers in the accomplishment of success. In established businesses, management practices are intuitively developed over a number of years. However, different people have different concepts of what management is about. That inevitably shapes their view about the way in which managers ought to learn and be developed, and it often gives rise to a number of contradictions and tensions (Devins, Gold, Johnson and Holden, 2005). Notwithstanding, personal traits can be used to modify the environmental business variables by an entrepreneur, but sometimes with difficulty. However, the modification of strategies is subsequent to venture creation through the determined efforts of the entrepreneur via his personal traits - intuitive abilities (Herron and Robinson, 1993).

Furthermore, the findings in Table 2 suggest a significant relationship between the ability to take risks and the success of the SME. One of the arguments that accounts for the secrets of SME success is the willingness to take risks (Makhbul and Hasun, 2011; Brinkman, 2000), through creativity and innovation, foresight and imagination, etc. Concurrently, Okafor (2010) adds that experience has shown that a successful entrepreneur takes careful calculated risks and neither must he/she shy away from necessary and unavoidable risks, which consequently results in tolerance of risk, ambiguity and uncertainty, creativity self-reliance and ability to adapt, and motivation required to be exhibited by SME managers in the pursuit of success. In the same vein, Arogundade (2009) states that failure of people to take risks, to a very high extent, affects the level of productivity and entrepreneurial activities in Nigeria. 
The findings in Table 3 indicate that the relationship between informal entrepreneurial management learning and the success of SME was significant. Research provides evidence that the nature of learning is on-going in SME business. In addition, learning is largely informal or incidental and driven by the desires of those involved and seldom reliant upon formal or structured training. Sometimes SME managers create deliberate attempts to experiment in order to acquire new knowledge, but more often than not, learning is the by-product of a business process rather than the focus of the process itself. As work proceeds and learning accumulates, meanings derived are shared among those who participate, forming the distinct culture of a business that develops over time. For instance, small business has been conceptualized as a learning organization operating within a network inter-dependent of others, including family members, friends, professional bodies, and other stakeholders, which culminates into increasing networks and networking and is viewed as a major learning opportunity for smaller enterprises, resulting in motivation of SMEs through observation of others (Devins, Gold, Johnson and Holden, 2005).

Through informal learning, values are also transmitted through wise sayings, proverbs, aphorisms, coded clauses, and experiential narrations, religious beliefs, principles, doctrines and practices, ancient fables, stories and folklores, poems, etc., reflective songs, powerful orations and incantations, etc., mythology and memories of elderly people, and shared-cultural values, such as shared customs, sayings, taboos, and superstitious (Ayozie and Latinwo, 2010).

\section{CONCLUSION}

This study has revealed that there is a significant relationship between personality traits, ability to undertake risks, and that informal learning of management results in the success of SME managers in Lagos State, Nigeria, despite the socio-economic impediments individual entrepreneurs might be contending with. As a result, enough evidence was provided in the literature review of this paper regarding the display of personal in-born characteristics, which results in self-initiative, self-regulations, and life-long learning skills in order to meet the needs and challenges of SME managers, despite that they did not experience or acquire formal management training as undergraduates during and after their university years.

In addition, the motivation of being able to utilize self-regulation through the exhibition of personal characteristics, such as self-confidence, locus of control, good communication, etc., can lead to successful entrepreneurship. The literature also provides that one of the important factors contributing to successful entrepreneurship success is the informal management knowledge and experiences gained from various sources, such as friends, family, peers and colleagues, etc. who provide informal managerial learning opportunities through mentoring, which accumulates as the years go by.

Lastly, it is also pertinent to note that the findings of this paper tilt toward Harron and Robinson's (1993:281-294) adapted theoretical model of entrepreneurship. The adapted model specifies that entrepreneurial performance (success) is a product of personality traits (values, attitudes, and expectations), which is a result of motivational goals and objectives and process of entrepreneurs (management, leadership, etc.). Every unsuccessful SME manager should look inward and attempt to discover some in-born management characteristics that lie within them in order to be successful as managers.

\section{RECOMMENDATIONS}

Based on the findings, the following recommendations are put forth:

1. Individual successful SME graduate managers should be identified by the government and supported by compulsory management appreciation acquisition programs.

2. The government may base the licensing of managers of SME businesses (that is, managers who are not formally trained) on the compulsory attendance of management appreciation classes in order to formalize their management knowledge.

3. SME managers, who are successful in their business due to the exhibition of intuitive management behavior, should consider upgrading their intuitive business management experience with the science of management through short, formal management trainings for optimal performance in their business. 
4. Every unsuccessful SME manager should look inward and attempt to discover some in-born management characteristics that lie within them in order to be successful as managers.

5. It is, however, recommended that male and female SME managers could be separately studied with regard to how they manage and succeed in their business, despite that they did not have experience of formal training in management.

\section{AUTHOR INFORMATION}

Ololade Kazeem Shonubi earned a Ph.D. Degree in the Department of Education Management, Law and Policy Studies at the University of Pretoria. He is currently a Post-doctoral Research fellow at the University of Johannesburg. His areas of interest are Education Leadership, Management and School Effectiveness, Education Policy Studies, Gender Studies and Educational Research Studies. He has published in recognized journals and has attended scholarly conferences locally and internationally. E-mail: loladeshonubi@yahoo.com (Corresponding author)

Saheeb Oluwafemi Taiwo is a Ph.D. student studying Finance at Walden University and a faculty member in the Department of Banking and Finance, Lagos State University, Lagos, Nigeria. He is author of four books including Statistics for Undergraduates, Monetary and Fiscal Theories, Feasibility Study and Techniques of Project Evaluation, and Selected Questions and Answers in Microeconomics, all published in Lagos, Nigeria. E-mail: saheeb.taiwo@waldenu.edu (Corresponding author)

\section{REFERENCES}

1. Amuseghan S.A and Tayo-Olajubutu O (2009). Spinning off an entrepreneurship culture among Nigerian University Students: Prospects and challenges. African Journal of Business Management, 3 (3), 080-088.

2. Arogundade, B.B (2009). Entrepreneurship education: An imperative for sustainable development in Nigeria: Journal of Emerging Trends in Educational Research and Policy Studies (JETERAPS), 2 (1), 2629.

3. Ayozie, D.O and Latinwo, H.K (2010). Entrepreneurial developments in small scale industry contribution to Nigerian national development- A marketing interface. Informational Management and Business Review, $1(2), 51-68$.

4. Cohen, L; Manion, L.A and Morrison, K (2007). Research Methods in Education (Sixth Edition). New York: Routledge.

5. Davins, D; Gold, J; Johnson, S and Holden, R (2005). A conceptual model of management learning in micro-businesses. Education and Training, 47 (8/9), 540-551.

6. $\quad$ Ekpe, I (2011). Women entrepreneurs and economic development in Nigeria: Characteristics for success. International Journal of Business and Social Science, 2 (1), 288-291.

7. Fink, M and Hatak, I (Editors) (2010). Current Research on Entrepreneurship and SME management, $7^{\text {th }}$ Edition of the Inter-Rent. An initiative of the European Council for Business and Entrepreneurship (ECSB), Tukur, Finland; ECBS.

8. Galbraith, C.S (2008). Economic development and entrepreneurship research. International Journal of Entrepreneurship and small Business, 6 (4), 517-519.

9. Grant, P and Perren, L (2002). Small business and entrepreneurial research: Meta-theories, paradigms and prejudices. International Small Business Journal, 20 (2), 185-211.

10. Hamerlinck, J and Emery, M (2006). Entrepreneuralship: A unique opportunity for higher education. North Central Regional Centre for Rural Development (NCRCRD) Policy Briefs, September.

11. Herron, L and Robinson, R. B (1993). A structural model of the effects of entrepreneurial characteristics on venture performance. Journal of Business Venturing, 8:281-294.

12. Johnson, B.R (1990). Towards a dimensional model of entrepreneurship: Theory and Practice, 14 (13), 39 54.

13. Kuratko, D.F. and Hodgetts, R.M (2004). Entrepreneurship: Theory, Process, Practice. Mason, OH: South Western College Publishers. 
14. Lewis, P (2006). The quest for invisibility: Female entrepreneurs and the masculine norm of entrepreneurship. Gender, Works and Organization. Gender in Management: An International Journal, 25 (1), 5-21.

15. Makhbul, Z.H and Hasun, F.M (2011). Entrepreneurial Success: An exploratory study among entrepreneurs. International Journal of Business Management, 6 (1), 116-125.

16. Maree, K and Pietersen, J (2007). Surveys and the use of questionnaires. In. Maree, K (Ed.). Fist Step in Research. Pretoria: Van Schaik Publishers.

17. Mordi, C; Simpson, R; Singh, S and Okafor, C (2010). The role of cultural values in understanding the challenges faced by the formal entrepreneurs in Nigeria. Gender, Management: An International Journal, 25 (1), 5-12.

18. Ngunjiri, I (2010). Corruption and entrepreneurship in Kenya. The Journal of Language, Technology in Africa, 2 (1), 93-106.

19. Ogunsiji, S.O (2010). Entrepreneurial orientation as a panacea for ebbing productivity in Nigerian small and medium entrepreneurial: A theoretical perspective. International Business Research, 3 (4), 192-199.

20. Okala, O.F (2004). Entrepreneurship skill development: An initiative to change the youths' attitude towards employment in Nigeria. Proceedings of the $19^{\text {th }}$ Annual Congress of the Nigerian Academy of Education held at the Lagos State University, Lagos, $22^{\text {nd }}-26^{\text {th }}$ November, 2004, pp.431-443.

21. Organization of Economic Cooperation and Development \{OECD\} (2004). Small and Medium Enterprises in Turkey: Issues and Policies. OECD, Paris.

22. Oviawe, J.I (2010). Repositioning Nigerian youths for economic empowerment through entrepreneurship education. European Journal of Educational Studies, 2 (2), 113-118.

23. www.answers.com/topic/management 